\title{
Evaluation of the Knowledge and Practice about Diabetes Mellitus of Adult Population in Porto Novo (Benin)
}

\author{
Finangnon Armand Wanvoegbe ${ }^{1 *}$, Kouessi Anthelme Agbodandé 2 , \\ Arnaulde Amoussou-Guenou Fandi ${ }^{3}$, Marius Boko', Adébayo Alassani², Annelie Kerekou², \\ Daniel Amoussou-Guenou ${ }^{2}$

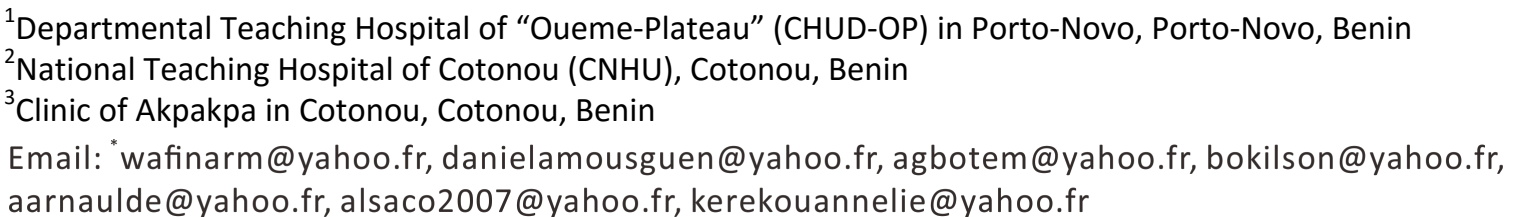

Received 24 July 2016; accepted 14 August 2016; published 17 August 2016

Copyright (C) 2016 by authors and Scientific Research Publishing Inc.

This work is licensed under the Creative Commons Attribution International License (CC BY). http://creativecommons.org/licenses/by/4.0/

(c) (;) Open Access

\begin{abstract}
Background: Diabetes mellitus is one of the most common non-communicable diseases in the world. The aim of our study was to assess the level of knowledge of the adult population of Porto-Novo on clinical manifestations and complications of diabetes mellitus. Methods: It is a descriptive crosssectional study conducted under STEP wise approach. It took place from June 1 to July $28,2014$. Results: A total of 240 subjects were included in the study. The mean age of the subjects was 46.07 years \pm 12.63 years, ranging from 25 to 80 years. Subjects age between $35-45$ years are the most represented. Women were mostly represented 162 against 78 men respectively $67.5 \%$ against $32.5 \%$ with sex ratio of 0.48 . The majority of the subjects were scholar (73.3\%). For clinical manifestations of diabetes mellitus, $64.2 \%$ of subjects had quoted polyuria, asthenia $57.5 \%$, $56.7 \%$ weight loss. Polydipsia and polyphagia were less familiar with, respectively, $27.5 \%$ and 23.3\%. Regarding the complications of diabetes, diabetic foot and coma were the best known, respectively, $78.8 \%$ and $58.8 \%$. Nephropathy $(45.0 \%), 39.6 \%$ retinopathy and neuropathy $(21.7 \%)$ were the least known. The prevalence of physical inactivity in this study population was $95.0 \%$. It was $\mathbf{9 8 . 1 \%}$ in women versus $\mathbf{8 8 . 5 \%}$ for men. Conclusion: Diabetes mellitus, whose prevalence is steadily increasing, is not yet well known in our population.
\end{abstract}

\section{Keywords}

Knowledge, Diabetes, Porto-Novo

\footnotetext{
"Corresponding author.
} 


\section{Introduction}

Diabetes mellitus is a major public health issue in the world by its increasing frequency, morbidity, mortality and its economic costs [1]. It is one of the most common non-communicable diseases worldwide [2] [3]. In 2013 Diabetes mellitus affects 381.8 million people in the world according to estimations by the IDF [4]. IDF expected this number to increase to 591.9 million in 2035; an increase of 55.0\% [4]. If the prevalence and progression of diabetes mellitus are well understood in Western countries, this is not the case in developing one, because of lack of reliable data [5] and particularly in Sub-Saharan Africa [6]. In Benin, various investigations have been conducted. Thus the prevalence of diabetes mellitus was: $1.1 \%$ in 2001 [7] and 2.6\% in 2007 nationally [8]. Therefore, various public awareness campaigns have been organized by the National Program against Non Communicable Diseases (PNLNMT). The aim of our study was to assess the level of knowledge of the adult population in Porto Novo on clinical manifestations and complications of diabetes mellitus. Porto-Novo is the capital of the Republic of Benin which is a country of the West Africa.

\section{Methods}

It is a descriptive cross-sectional study conducted according to STEP wise approach recommended by the WHO to screening and monitoring of risk factors for non-communicable diseases [9]. It was a random sampling technique, stratified clusters. It took place from June 1 to July 28, 2014. The target population consisted of adults of five townships of Porto-Novo were included in the study, subjects aged at least 25 years to 80 years at most, regardless of sex, residing in Porto-Novo and consenting. These people were subjected to a questionnaire prepared for this purpose. The required number of participants obtained by Schwartz formula was 211. The number found was increased by $10 \%$ to account for non-respondents, giving a size of 232 subjects. A total of 240 subjects were included in the study. HBP was defined as BP equal or higher than 140/90 mm Hg. Obesity was defined as BMI equal or higher than $30 \mathrm{~kg} / \mathrm{m}^{2}$.

The collected data were analyzed with Excel and the EPI INFO software version 3.5.3.

\section{Results}

\subsection{General Characteristics of the Population}

The mean age of the subjects was 46.07 years \pm 12.63 years, ranging from 25 to 80 years. Age subjects between 35 - 45 years are the most represented.

Women were mostly represented 162 against 78 men respectively $67.5 \%$ against $32.5 \%$ with sex ratio of 0.48 . Traders were most represented (46.7\%) in this population (Table 1 ).

The majority of the subjects were scholar (73.3\%). 28.4\% of them are obese and 3.3\% have diabetes in their family.

\subsection{Evaluation of Knowledge of the Respondents on Diabetes Mellitus}

Cardinal symptoms of diabetes mellitus:

\section{Polyuria}

\begin{tabular}{ccc|}
\hline Table 1. Distribution of subjects according to their occupation. \\
\hline Occupation & Number & Percentage \\
\hline Official & 24 & 10.0 \\
Trader & 112 & 46.7 \\
Student/pupil & 6 & 2.5 \\
Craftsman & 45 & 188 \\
Housewife & 34 & 14.2 \\
Other & 19 & 7.9 \\
Total & 240 & 100 \\
\hline
\end{tabular}


$64.2 \%$ of subjects had cited as a symptom of diabetes mellitus.

Asthenia

It was cited by $57.5 \%$ of subjects.

Emaciation

$56.7 \%$ of subjects had itemized it.

Polydipsia

$72.5 \%$ of the subjects were unaware, so only $27.5 \%$ of the subjects knew it as a sign of diabetes.

Polyphagia

It was cited by $23.3 \%$ of the respondents.

\subsection{The Most Frequent Complications of Diabetes Mellitus}

\section{The diabetic foot}

This is the most known complication by the surveyed subjects (78.8\%).

\section{Coma}

$58.8 \%$ had quoted a coma from complications of diabetes mellitus.

\section{Nephropathy}

It was cited by $45.0 \%$ of subjects.

Retinopathy

$39.6 \%$ of subjects had quoted.

\section{Neuropathy}

The majority of subjects in our study (78.3\%) were unaware of.

\subsection{Feeding Behavior}

The average number of meals consumed per day was 2.7 ( 3 meals) \pm 0.59 with extremes ranging from 1 to 5 meals.

Snacking was noted in $65.0 \%(\mathrm{n}=156)$ in the overall population.

The fruits are consumed by $91.3 \%$ of subjects with an average frequency of consumption of fruit per week of 3.31 ( 3 times/week) \pm 2.31 , with a range from 1 to 14 times.

For vegetables, they are consumed by $95.0 \%$ of subjects with an average frequency of vegetables consumption per week of 1.83 (2 times/week) \pm 1.2 , with a range of 1 to 7 times.

\subsection{Prevalence of Physical Inactivity (Sedentary Lifestyle)}

The average frequency of sport per week is 1.92 times ( 2 times/week) \pm 1.4 with extremes ranging from 1 to 7 times.

The prevalence of physical inactivity in this study population was $95.0 \%(\mathrm{n}=228)$. It was $98.1 \%$ in women versus $88.5 \%$.

\section{Discussion}

Regarding the clinical manifestations of diabetes mellitus, polyuria is the most known symptom (64.2\% of subjects had cited as a symptom of diabetes mellitus) followed by asthenia (cited by $57.5 \%$ of subjects), weight loss (56.7\%). Polydipsia and polyphagia are the least known symptoms (27.5\% and 23.3\% polydipsia for polyphagia). We can therefore understand that the clinical manifestations of diabetes mellitus are not yet well known by the people of Porto-Novo, despite the various awareness campaigns that apparently have not yet reached the majority of the population.

This lack of knowledge about diabetes was also noted by Katchunga P.B. et al. in South Kivu [10]. Tessaro I. et al. had the same notice in an Appalachian population [11].

Regarding the complications, diabetic foot is the most known complication (78.8\%) because it is the most remarkable complication. The idea that a wound in a diabetic patient takes a long time to heal is very generally spread. Acute complications are also known by more than half of our study population (58.8\%). Other complications are less known.

The average number of meals consumed per day was 2.7 ( 3 meals) \pm 0.59 with extremes ranging from 1 to 5 
meals. But snacking was noted in $65.0 \%$ in the overall population. That percentage is so high and proves that our population needs an education about the feeding behavior.

The fruits are consumed by $91.3 \%$ of subjects with an average frequency of consumption of fruit per week of 3.31 ( 3 times/week) \pm 2.31 . Vegetables are consumed by $95.0 \%$ of subjects with an average frequency of vegetables consumption per week of 1.83 ( 2 times/week) \pm 1.2 . That consumption is not enough and should be further encouraged through awareness campaigns.

The prevalence of physical inactivity in the study population was $95.0 \%(n=228)$. It was $98.1 \%$ in women versus 88.5\%. This high prevalence of inactivity was also found in Cotonou by Kerekou A. et al. in 2011 [12], which show the lack of awareness of our population on diabetes mellitus prevention.

This study was limited in Porto-Novo and in view of these results, it is important that it be done at national level.

\section{Conclusion}

Diabetes mellitus, whose prevalence is steadily increasing, is not yet well known in our very inactive population. It is therefore imperative to intensify sensitization and campaigns actions to slow the progression of the disease, which is globally a public health issue now.

\section{References}

[1] Wild, S., Roglic, G., Green, A., Sicree, R. and King, H. (2004) Global Prevalence of Diabetes: Estimates for the Year 2000 and Projections for 2030. Diabetes Care, 27, 1047-1053. http://dx.doi.org/10.2337/diacare.27.5.1047

[2] Shaw, J.E., Sicree, R.A. and Zimmet, P.Z. (2010) Global Estimates of the Prevalence of Diabetes for 2010 and 2030. Diabetes Research and Clinical Practice, 87, 4-14. http://dx.doi.org/10.1016/j.diabres.2009.10.007

[3] Whiting, D.R., Guariguata, L., Weil, C. and Shaw, J. (2011) IDF Diabetes Atlas: Global Estimates of the Prevalence of Diabetes for 2011 and 2030. Diabetes Research and Clinical Practice, 94, 311-321. http://dx.doi.org/10.1016/j.diabres.2011.10.029

[4] Guarignata, L., Whiting, D.R., Beagley, J., Linnenkamp, U., Hambleton, I., Cho, N.H., et al. (2013) Global Estimates of Diabetes Prevalence in Adults for 2013 and Projection for 2035 for the IDF Diabetes Atlas. Diabetes Research and Clinical Practice, 103, 137-149. http://dx.doi.org/10.1016/j.diabres.2013.11.002

[5] Labie, D. (2007) Diabetes in sub-Saharan Africa. Médecine Sciences (Paris), 23, 320-322. http://dx.doi.org/10.1051/medsci/2007233320

[6] Mbanya, J.C., Motala, A.A., Sobngwi, E., Assah, F.K. and Enoru, S.T. (2010) Diabetes in Sub-Saharan Africa. The lancet, 375, 2254-2266. http://dx.doi.org/10.1016/S0140-6736(10)60550-8

[7] Djrolo, F., Amoussou-Guénou, K.D., Zannou, D.M., Houinato, D., Ahouandogbo, F., et al. (2003) Prevalence of diabetes mellitus in Benin. Louvain Médical, 122, S258-S262.

[8] Final Report of the STEPS Survey in Benin. (2008) Direction Nationale de la Projection Sanitaire, Programme Nationale de Lutte contre les Maladies Non Transmissibles.

[9] World Health Organization (WHO). The WHO STEPS Surveillance Manual (2005) The WHO STEP Wise Approach to Surveillance of Chronic Disease Risk Factors-4. Surveillance Manual WHO STEPS. World Health Organization, Geneva.

[10] Katchunga, P.B., Malanda, B., Mweze, M.C., Dupont, B., M’Buyamba-Kabangu, J.R., et al. (2012) Knowledge of the General Population on Hypertension and Diabetes Mellitus in South Kivu, Democratic Republic of Congo. Revue d'épidémiologie et de santé publique, 60, 141-147. http://dx.doi.org/10.1016/j.respe.2011.10.005

[11] Tessaro, I., Smith, S.L. and Rye, S. (2005) Knowledge and Perception of Diabetes in a Population of Appalachia. Preventing Chronic Disease, 2, 1-9. http://www.cdc.gov/pcd/issues/2005/apr/04_0098_fr.htm

[12] Kerekou, A., Azon Kouanou, A., Bocovo, M., Amoussou-Guenou, D., Djrolo, F., et al. (2014) Prevalence of Physical Activity in External Medicine at CNHU/HKM in Cotonou. Médecine d'Afrique Noire, 61, 592-596. 


\section{Submit or recommend next manuscript to SCIRP and we will provide best service for you:}

Accepting pre-submission inquiries through Email, Facebook, LinkedIn, Twitter, etc.

A wide selection of journals (inclusive of 9 subjects, more than 200 journals)

Providing 24-hour high-quality service

User-friendly online submission system

Fair and swift peer-review system

Efficient typesetting and proofreading procedure

Display of the result of downloads and visits, as well as the number of cited articles

Maximum dissemination of your research work

Submit your manuscript at: http://papersubmission.scirp.org/ 